\title{
A Case of Hydranencephaly in Which Ophthalmic Examinations Were Performed
}

\author{
Shohei Eda $a^{a, b}$ Tomoko Terai ${ }^{a, b} \quad$ Yuko Nishikawa $^{a} \quad$ Masahiro Tonari $^{a}$ \\ Teruyo Kida $^{a}$ Hidehiro Oku $^{a}$ Jun Sugasawa ${ }^{a}$ Shuichi Shimakawa ${ }^{c}$ \\ Masashi Hasegawa ${ }^{d}$ Tohru Ogihara $^{d}$ Tsunehiko Ikeda $^{a}$ \\ ${ }^{a}$ Department of Ophthalmology, Osaka Medical College, Takatsuki City, Japan; \\ ${ }^{b}$ Department of Ophthalmology, Shiga Medical Center for Children, Moriyama, Japan; \\ 'Department of Pediatrics, Osaka Medical College, Takatsuki City, Japan; ${ }^{d}$ Department of \\ Neonatology, Osaka Medical College, Takatsuki City, Japan
}

\section{Keywords}

Hydranencephaly · Magnetic resonance imaging · Optical coherence tomography ·

Electroretinogram

\begin{abstract}
Purpose: We performed ophthalmic examinations, including optical coherence tomography (OCT), on a case diagnosed with hydranencephaly. Case Report: This case involved a female infant born at the gestational age of 35 weeks and 4 days, with the birth weight of 2,152 g, who was one of monochorionic diamniotic twins, and the identical twin died in utero at the gestational age of 24 weeks. After that, examination by fetal echo indicated that she had microcephaly and ventriculomegaly. Postnatal magnetic resonance imaging (MRI) of her head indicated microcephaly and significant enlargement of the lateral ventricle on both sides, with no obvious signs of elevated intracranial pressure. The brain parenchyma of both sides of the frontal lobe, parietal lobe, and occipital lobe had marked thinning, yet that of the temporal lobe, basal ganglia, thalamus, brain stem, and cerebellum had been maintained. Moreover, no obvious hematoma or neoplastic lesions were observed. Ophthalmic examinations indicated that both of her eyes had slight light reflex, attributed to optic nerve atrophy. Examination by use of a hand-held OCT system indicated a layered structure of the retina
\end{abstract}




\section{Case Reports in Ophthalmology}

Case Rep Ophthalmol 2016;7:142-147

DOI: 10.1159/000449123

c 2016 The Author(s). Published by S. Karger AG, Basel www.karger.com/cop

Eda et al.: A Case of Hydranencephaly in Which Ophthalmic Examinations Were Performed

and thinning of the ganglion cell layer. Flicker electroretinogram (ERG) examination by use of a hand-held ERG system indicated an almost normal wave. However, no clear visual reaction was observed when she was 10 months old. Conclusion: Our findings in this case of hydranencephaly revealed that even though the outer layer functions of the patient's retina were maintained, extensive damage to her cerebral cortex resulted in poor visual function.

(C) 2016 The Author(s)

Published by S. Karger AG, Basel

\section{Introduction}

Hydranencephaly is a rare condition in which the brain's cerebral hemispheres are absent to varying degrees, and the remaining cranial cavity is filled with cerebrospinal fluid and is covered by a membrane-like sac consisting of a buffy coat and arachnoid. However, the brain stem is still present in such cases. The results of magnetic resonance imaging (MRI) examination of the head show almost complete defect of cerebral hemisphere with remaining membrane sac attached by residual frontal, temporal, and parietal lobes, which are clearly different from those of hydrocephalus [1,2]. Reportedly, ocular complications associated with hydranencephaly include pupillary abnormalities, strabismus, nystagmus, ptosis, optic nerve hypoplasia, chorioretinitis, narrowing of the retinal blood vessels, and anterior chamber division syndrome, etc. [3-9]. In this present study, we performed ophthalmic examinations by use of hand-held optical coherence tomography (OCT) and a hand-held electroretinogram (ERG), in addition to general ophthalmic examinations, in a patient diagnosed with hydranencephaly.

\section{Case Report}

This study involved a female infant, born at the gestational age of 35 weeks and 4 days and with a birth weight of 2,152 g. She was one of monochorionic diamniotic twins, and her identical twin died in utero at the gestational age of 24 weeks. After that, the results of examination by fetal echo indicated that she had microcephaly and ventricular enlargement. Postnatal MRI of the patient's head showed microcephaly and significant enlargement of the lateral ventricle on both sides with no obvious signs of elevated intracranial pressure. The brain parenchyma on both sides of the frontal lobe, parietal lobe, and occipital lobe had marked thinning, yet that of the temporal lobe, basal ganglia, thalamus, brain stem, and cerebellum had been maintained (fig. 1a-c). In addition, no indications of obvious hematoma or neoplastic lesions were observed. Moreover, she had no obvious family history of ocular and systemic diseases.

The patient underwent fundus examination at 1 week after birth. Slight light reflex was observed in both eyes, yet it was very weak. The anterior chamber of each eye was a little shallow, but no abnormal findings of the anterior segment were observed, such as pupil abnormalities, cataracts, strabismus, nystagmus, and ptosis. The fundus of both eyes indicated optic nerve atrophy, but the degree of pallor was mild. Moreover, our findings, although incomplete, led us to suspect a peripapillary ring (the double-ring sign) around the optic disc. The color of the fundus was weak and of a reddish tone, yet no abnormality was found in the diameter and development of the retinal vessels, which normally extend to the peripheral portion of the fundus. Moreover, no obvious chorioretinal dysplasia was observed (fig. 2a, b). 
Eda et al.: A Case of Hydranencephaly in Which Ophthalmic Examinations Were Performed

Examination by use of a hand-held OCT system (iVue OCT System; Optovue, Inc., Fremont, Calif., USA) showed that the outer structure of the retina in both eyes still remained. Compared to normal infants, no fovea depression was observed, yet the retinal ganglion cell layer was found to be thinner (fig. 3a, b). Examination by use of a hand-held flicker ERG (RETeval ${ }^{\mathrm{TM}}$ Visual Electrodiagnostic System; LKC Technologies, Inc., Gaithersburg, Md., USA) system showed a relatively good waveform in both eyes (fig. $4 \mathrm{~b}, \mathrm{~b}$ ). At present, she is 10 months old already; however, she still lacks obvious visual reflex, such as the movement of her eyes to follow moving objects.

\section{Discussion}

It has been reported that hydranencephaly is caused by ischemia, hemorrhage, infarction, or trauma occurring in the fetal stage of life, and that the occlusion of the epithalamus of the internal carotid artery during the fetal stage is the most frequent cause $[1,2]$. In fact, it is seen in $0.2 \%$ of the autopsies of newborns. About $1 \%$ of hydrocephalus cases are thought to be hydranencephaly. Clinical symptoms, such as neonatal seizures, myoclonus, and respiratory failures can occur during the first few weeks after birth, and the vital prognosis is reportedly poor [10]. Even though there is no intracranial pressure elevation, optic nerve atrophy can occur and primitive reflex is persistent, both due to cerebral damage. The diagnostic approach for hydranencephaly is based on the head translucency test, yet the disorder is often discovered by fetal diagnosis or by head ultrasound examination when the mother is admitted to a neonatal facility. There is currently no treatment for hydranencephaly, however, a postnatal ventriculo-peritoneal shunt can be performed to prevent the enlargement of head circumference [11].

Hydrocephalus, a differential diagnosis, refers to the condition in which cerebrospinal fluid is excessively stored in the ventricle and the subarachnoid space, due to overproduction or impaired absorption of the fluid, or obstruction [12]. Clinically, head circumference enlargement, bulging anterior fontanelles, etc., are observed, but hydrocephalus that has developed slowly exhibits such symptoms as developmental disorders and blurred vision, which may be diagnosed for the first time. In this present case, we observed microcephaly without the enlargement of the head circumference and no obvious signs of elevated intracranial pressure.

Another disease that ought to be differentially diagnosed is destructive hydrocephalus. It is caused by a circulation disorder of the cerebrospinal fluid and to be distinguished from hydrocephalus with dilated ventricles due simply to increased intraventricular pressure. In this disease, dilatation of the ventricles occurs irregularly and rapidly, leading to secondary cerebral destruction [13]. In terms of its differences from hydranencephaly, there are many cases in which enlargement of the ventricles is relatively irregular, compared to hydranencephaly. The present case was negative in that regard, based on the MRI findings.

In our case, ventricular dilatation progressed in utero only after death of her identical twin was confirmed. Therefore, it is possible that thrombophilic conditions derived from dead twin through connective vessels resulted in cerebral infarction and hemorrhage.

Reportedly, ocular complications associated with hydranencephaly include pupillary abnormalities, strabismus, nystagmus, ptosis, optic nerve hypoplasia, chorioretinitis, narrowing of the retinal blood vessels, and anterior chamber division syndrome [3-9]. In addition, previous studies have reported a peripapillary ring around the optic nerve head [8]. Although incomplete, the findings in this present case are similar. 
Eda et al.: A Case of Hydranencephaly in Which Ophthalmic Examinations Were Performed

There have been a few reports on the histological examination of the retina in cases of hydranencephaly [7-9]. Among those studies, some have shown that the inner granular layer, outer plexiform layer, photoreceptor cell layer, and retinal pigment epithelial cell layer were almost normal, yet marked thinning or loss of retinal ganglion cell layer was observed [14]. Although OCT findings of infants are known to be slightly different from those of adults, past reports have shown that the ganglion cell layer is also seen in infancy. Based on the hand-held OCT findings in the present case, the retinal ganglion cell layer was markedly thin in comparison to that of normal, consistent with the pathological results in previous reports. Furthermore, we theorize that it was caused by the atrophy of the optic nerves, attributed to the thinning of the ganglion cell layer. To the best of our knowledge, this is the first case to undergo OCT for hydranencephaly, and we believe that our findings will be of interest. The results of the flicker ERG examination in this case showed an almost normal waveform, thus indicating that the photopic function of the retina had been maintained. These results are consistent with the pathological results in the previous reports, as well as with the OCT findings in this study.

In conclusion, even though our patient is now 10 months old, she has yet to show any visual reaction. Sadly, due to the high degree of thinning of the occipital lobe caused by hydranencephaly, we do not expect the patient's visual functions to develop in the future [15].

\section{Acknowledgements}

The authors wish to thank John Bush for editing the manuscript.

\section{Statement of Ethics}

This case study has been approved by the Ethics Committee of the Osaka Medical College.

\section{Disclosure Statement}

The authors have no conflicts of interest to report.

\section{References}

1 Cecchetto G, Milanese L, Giordano R, Viero A, Suma V, Manara R: Looking at the missing brain: hydranencephaly case series and literature review. Pediatr Neurol 2013;48:152-158.

-2 Pavone P, Praticò AD, Vitaliti G, Ruggieri M, Rizzo R, Parano E, Pavone L, Pero G, Falsaperla R: Hydranencephaly: cerebral spinal fluid instead of cerebral mantles. Ital J Pediatr 2014;40:79.

-3 Herman DC, Bartley GB, Bullock JD: Ophthalmic findings of hydranencephaly. J Pediatr Ophthalmol Strabismus 1988;25:106-111.

-4 Storm RL, PeBenito R: Bilateral optic nerve aplasia associated with hydranencephaly. Ann Ophthalmol 1984;16:988-992.

5 Watts P, Kumar N, Ganesh A, Sastry P, Pilz D, Levin AV, Chitayat D: Chorioretinal dysplasia, hydranencephaly, and intracranial calcifications: pseudo-TORCH or a new syndrome? Eye (Lond) 2008;22:730-733.

-6 Porro G, Wittebol-Post D, de Graaf M, van Nieuwenhuizen O, Schenk-Rootlieb AJ, Treffers WF: Development of visual function in hemihydranencephaly. Dev Med Child Neurol 1998;40:563-567. 
Eda et al.: A Case of Hydranencephaly in Which Ophthalmic Examinations Were Performed

7 Hill K, Gogan DG, Dodge PR: Ocular signs associated with hydranencephaly. Am J Ophthalmol 1961;51:267-275.

-8 Manschot WA: Eye findings in hydranencephaly. Ophthalmologica 1971;162:151-159.

-9 Ushigusa T, Uchida K, Murakami T, Yamaguchi R, Tateyama S: A pathologic study on ocular disorders in calves in southern Kyushu, Japan. J Vet Med Sci 2000;62:147-152.

10 Bae JS, Jang MU, Park SS: Prolonged survival to adulthood of an individual with hydranencephaly. Clin Neurol Neurosurg 2008;110:307-309.

11 Shitsama S, Wittayanakorn N, Okechi H, Albright AL: Choroid plexus coagulation in infants with extreme hydrocephalus or hydranencephaly. J Neurosurg Pediatr 2014;14:55-57.

12 Del Bigio MR: Neuropathology and structural changes in hydrocephalus. Dev Disabil Res Rev 2010;16:16-22.

13 Nakamura S, Tsubokawa T: Destructive hydrocephalus: a proposed new category. Childs Nerv Syst 1986;2:101-104.

14 Vinekar A, Mangalesh S, Jayadev C, Maldonado RS, Bauer N, Toth CA: Retinal imaging of infants on spectral domain optical coherence tomography. Biomed Res Int 2015;2015:782420.

15 Werth R: Residual visual function after loss of both cerebral hemispheres in infancy. Invest Ophthalmol Vis Sci 2007;48:3098-3106.
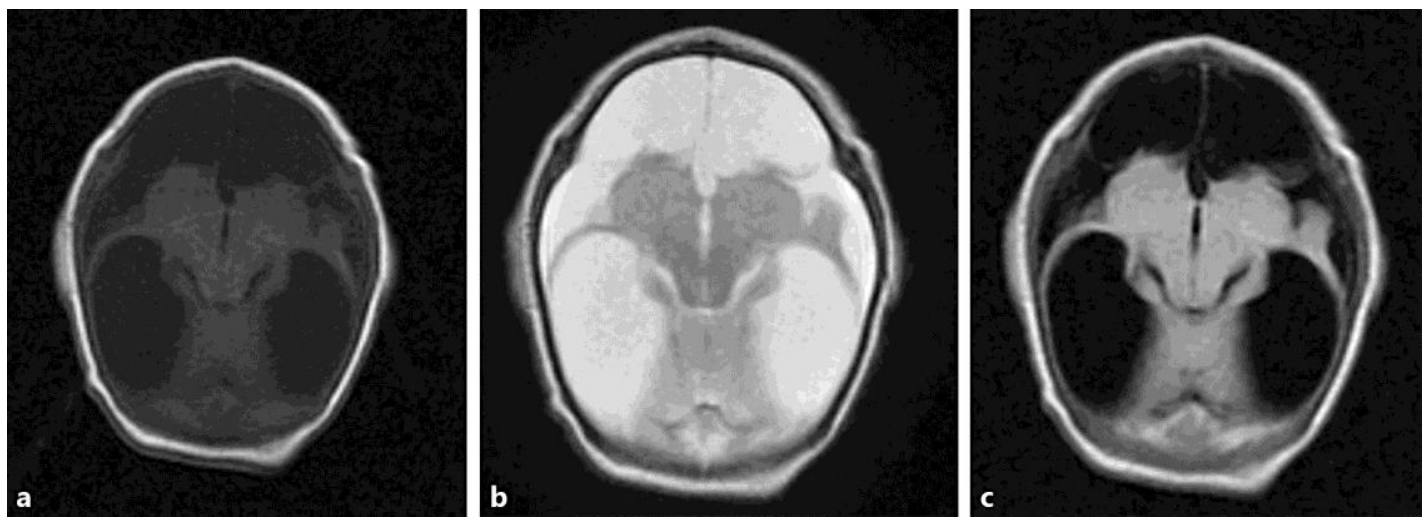

Fig. 1. Postnatal MRI findings. a T1-emphasized image; b T2-emphasized image; c FLAIR image. The brain parenchyma on both sides of the frontal lobe, parietal lobe, and occipital lobe show marked thinning, yet that of the temporal lobe, basal ganglia, thalamus, brain stem, and cerebellum is maintained. 


\section{Case Reports in Ophthalmology}

\begin{tabular}{l|l}
\hline Case Rep Ophthalmol 2016;7:142-147 \\
\hline DOI: 10.1159/000449123 & $\begin{array}{l}\text { @ 2016 The Author(s). Published by S. Karger AG, Basel } \\
\text { www.karger.com/cop }\end{array}$ \\
\hline
\end{tabular}

Eda et al:: A Case of Hydranencephaly in Which Ophthalmic Examinations Were Performed
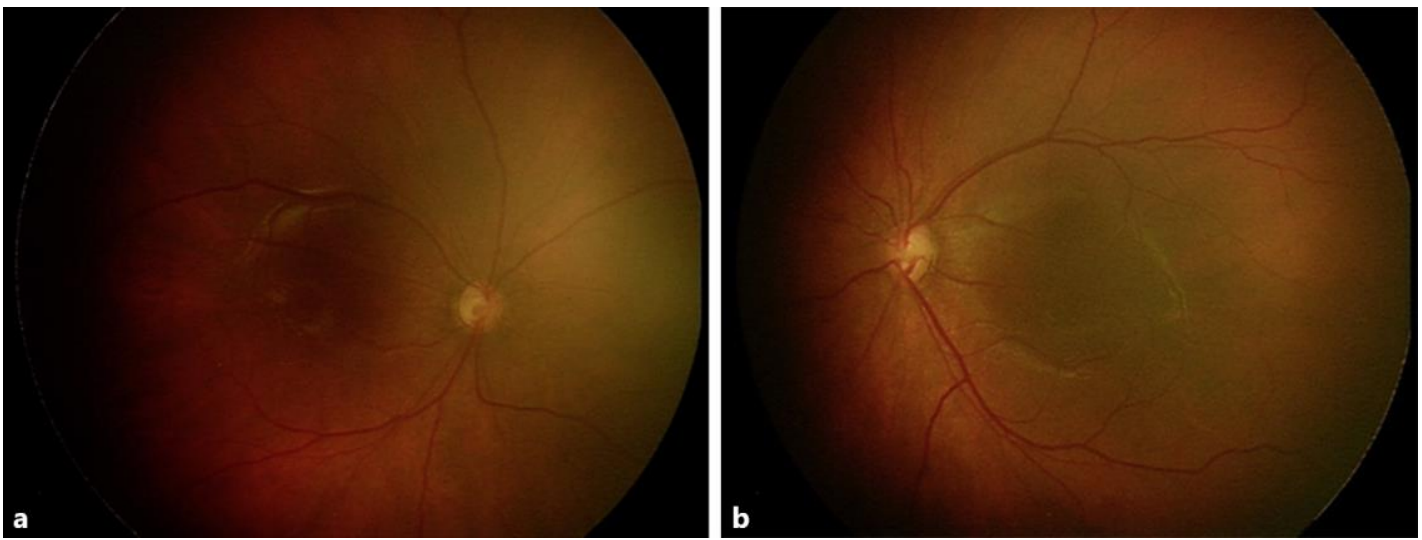

Fig. 2. Fundus photographs on initial examination (a shows the right eye; $\mathbf{b}$ shows the left eye). The fundus of both eyes indicated optic nerve atrophy, and we suspected a peripapillary ring (the double-ring sign) around the optic disc.
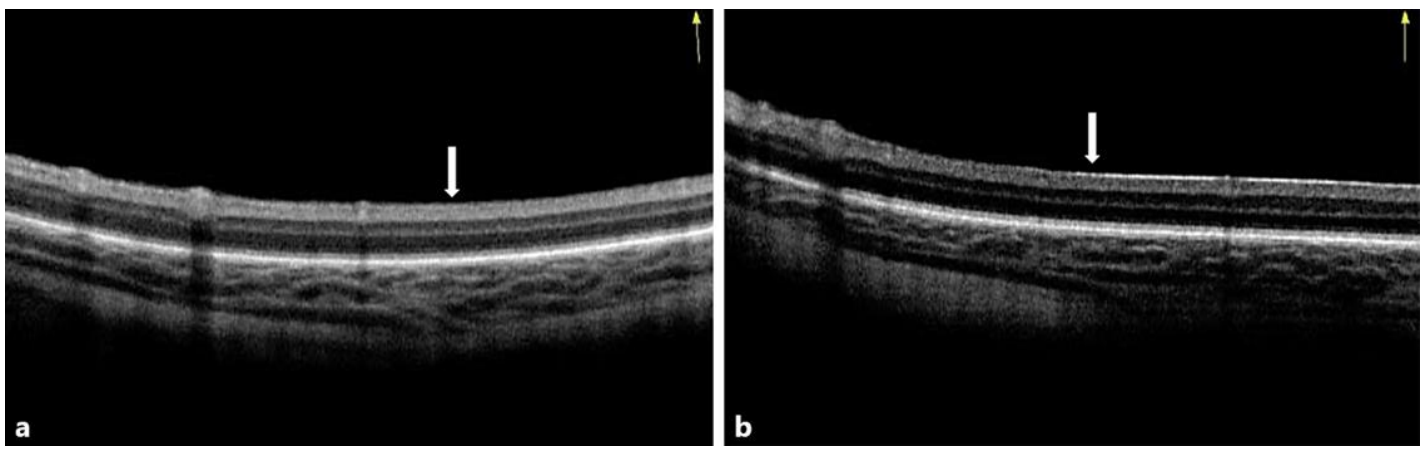

Fig. 3. Hand-held OCT findings (a shows the right eye; b shows the left eye). OCT examination indicated that the outer structure of the retina in both eyes still remained. No fovea depression can be observed, and the retinal ganglion cell layer is thin compared to normal infants.
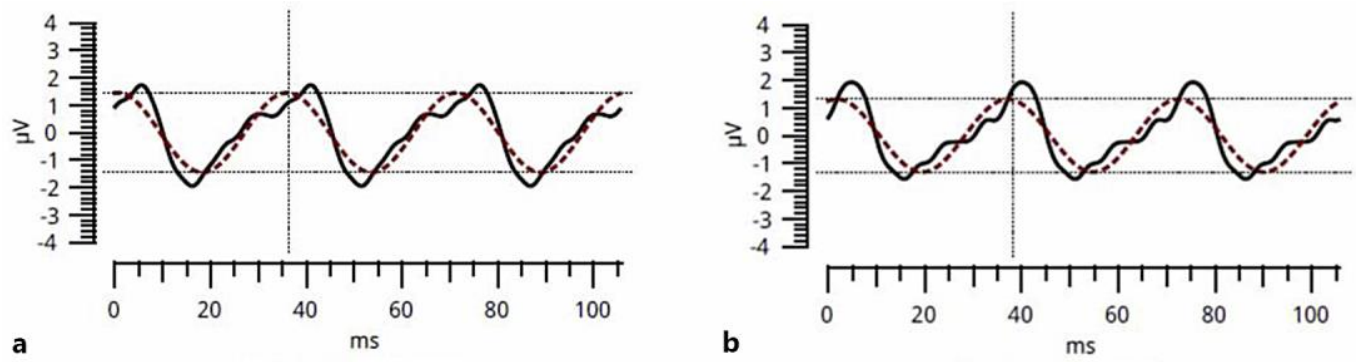

Fig. 4. The hand-held ERG recording (a shows the right eye; $\mathbf{b}$ shows the left eye). ERG examination revealed a relatively good waveform in both eyes. 